\title{
Effect Of Television Watching On Vision Of School Children In Rural Haryana.
}

\author{
S Seema, V BM, K AK, K Minakshi, G Manish
}

\begin{abstract}
Citation
S Seema, V BM, K AK, K Minakshi, G Manish. Effect Of Television Watching On Vision Of School Children In Rural Haryana.. The Internet Journal of Preventive Medicine. 2011 Volume 2 Number 1.
\end{abstract}

DOI: $\underline{10.5580 / 1 \mathrm{e} 04}$

\begin{abstract}
Objectives: To study the Effect of different factors associated with TV watching on vision in school children (6-15 years). Study Design: Cross-sectional. Setting: Govt. Senior Secondary Schools of Block Lakhanmajra. Participants: 1265 school children (6-15 years). Methodology: Out of 16 Govt. Senior Secondary Schools, 4 were randomly chosen. Students aged 6-15 years studying in class 1 to 10 were included in the study. Visual Acuity (VA) test was performed using Snellen's $E$ chart and an interview was done on the basis of questionnaire. The findings of clinical examination were recorded on a pre-tested Performa and were analyzed. Statistical Analysis: percentages, Chi-square test. Result: Out of 1265, 93 students did not watch TV. Out of the remaining 1172, 161 students (13.7\%) had defective vision. Out of 109 students (9.3\%) who watched TV in darkness, 24 students (22\%) had defective vision. Out of 129 students (11\%) who watched TV from a distance of less then 5 feet, 27 students $(20.9 \%)$ had defective vision. Out of 914 students (78\%) who watched TV from a distance 5-10 feet, 113 students $(12.4 \%)$ had defective vision and out of 129 students (11\%) who watched TV from a distance $>10$ feet, 21 students (16.3\%) had defective vision. Prevalence of defective vision was more in cases of longer duration of TV watching, Conclusion: Distance, duration and environment of television watching may be responsible for impairing a child's visual development. Defective vision can have a long term impact on the learning abilities of school children.
\end{abstract}

TV rots the senses in the head! It kills the imagination dead! It clogs and clutters up the mind! It makes a child so dull and blind. He can no longer understand a fantasy, A fairyland! His brain becomes as soft as cheese! His powers of thinking rust and freeze! An excerpt from Charlie and the Chocolate Factory, By Roald Dahl, $1964^{1}$

\section{INTRODUCTION}

Children aged 5-15 years studying in primary and/or secondary classes are susceptible to various types of the eye diseases. Early detection through regular checkup and prompt treatment will help in prevention of serious complication such as blindness. Extended close viewing of a TV can cause eye strain and fatigue as reflected by neck and shoulder problems, headache, blurred vision, double vision, red or watery or dry eyes and pain around the eyes and face ${ }^{2}$.

Your child's vision is the most important tool he/she has to succeed in school. When his/her vision suffers, chances are his schoolwork does, too. In fact, up to 25 percent of schoolchildren may have vision problems that can affect their ability to learn, according to the College of Optometrists in Vision Development School-age children also spend a lot of time in recreational activities that require good vision. After-school team sports or playing in the backyard aren't as fun if you can't see well ${ }^{3}$.

Refractive error is an optical defect intrinsic to the eye which prevents the light from being brought to a single point focus on the retina thus reducing normal vision ${ }^{4}$. Refractive errors are common in children and are easily correctable, usually with the use of the spectacles. These are the commonest cause of visual impairment around the world and the second leading cause of treatable blindness ${ }^{5}$. Refractive errors may appear throughout childhood and adolescence. If refractive errors are left untreated they can result in amblyopia and or strabismus ${ }^{6}$.

\section{OBJECTIVES}

To study the Effect of different factors associated with TV 
watching on vision in school children (6-15 years).

\section{MATERIAL AND METHODS}

The present cross-sectional study was carried out from September 2006 to July 2007 in block Lakhanmajra, which is the field practice area attached to the department of Community Medicine, Pt. B.D. Sharma Post Graduate Institute of Medical Sciences, Rohtak. The study subjects were school going children in the age group of 6-15 years. Children are chosen because if defective vision is detected early in life then it could be rectified quickly. Out of total 16 Govt. schools existing in the block, two girls' schools and two boys' schools were randomly selected and all the students between 6-15 years of age, studying in class $1{ }^{\text {st }}$ to $10^{\text {th }}$ were included in the study. The students were divided in to three age groups: 6-10 years, 10-13 years and 13-15 years. All concerned Principals, teachers and students were briefed about the study. Each student was interviewed individually by the author in their local language so that they can understand questions easily. The students present on day of visit were included in the study. No follow up visits were done. The age of students was ascertained as per the school records. Visual Acuity (VA) test was performed using Snellen's E chart. If distant visual acuity was $<6 / 6$, then those students were subjected to refraction by ophthalmic assistant. VA $<6 / 6$ was taken as criteria of defective vision because criterion of low vision according to WHO (VA $\leq 6 / 18$ in better eye) is already grossly subnormal for school children.

Information was collected on a pre-tested semi structured schedule. After collection, the whole data was compiled; analyzed (SPSS-10) and appropriate statistical tests like percentages and chi-square $\left(\square^{2}\right)$ test were applied.

\section{RESULTS}

Out of 1265, 93 students did not watch TV. Out of the remaining 1172 , 161 students $(13.7 \%)$ had defective vision. Out of 109 students $(9.3 \%)$ who watched TV in darkness, 24 students $(22 \%)$ had defective vision. The defective vision was significantly associated with darkness during TV viewing $(\mathrm{p}<0.01)$.

Out of total 1172 students who watched TV, 129 students (11\%) who watched TV from a distance of less then 5 feet, 27 students $(20.9 \%)$ had defective vision. Out of 914 students (78\%) who watched TV from a distance 5-10 feet, 113 students $(12.4 \%)$ had defective vision and out of 129 students $(11 \%)$ who watched TV from a distance $>10$ feet,
21 students $(16.3 \%)$ had defective vision. It was observed that TV watching from a distance of less then 5 feet was significantly associated with defective vision $(\mathrm{p}<0.05)$.

In this study it was observed that prevalence of defective vision was more in cases of longer duration of TV watching, but the association of duration was not found to be significant with defective vision.

Table I shows, the prevalence of defective vision (VA <6/6) was much more $(22 \%)$ in students who watched TV in darkness as compared to those $(12.9 \%)$ who watched TV in light. The association of defective vision with darkness during TV watching was found to be highly significant.

\section{Figure 1}

Table: I Relation of defective vision with light/darkness during TV watching

\begin{tabular}{|c|c|c|c|}
\hline \multirow{2}{*}{ Lighting } & \multicolumn{2}{|c|}{ Vision } & \multirow{2}{*}{ Total } \\
\cline { 2 - 3 } Condition & Defective & Normal & \\
& {$[\%]$} & {$[\%]$} & {$[\%]$} \\
\hline \multirow{2}{*}{ Light } & 137 & 926 & 1063 \\
& {$[12.9]$} & {$[87.1]$} & {$[100]$} \\
\hline Darkness & 24 & 85 & 109 \\
& {$[22]$} & {$[78]$} & {$[100]$} \\
\hline Total & 161 & 1011 & 1172 \\
& {$[13.7]$} & {$[86.3]$} & {$[100]$} \\
\hline
\end{tabular}

$\square^{2}=6.905(\mathrm{df}-1), \mathrm{P}<0.01$

Table II shows the prevalence of defective vision was more in students $(20.9 \%)$ who used to watch TV from a distance of $<5$ feet as compared to those $(12.8 \%)$ who watched from a distance $>5$ feet. The association of distance of TV watching with defective vision was found to be significant.

\section{Figure 2}

Table: II Relation of defective vision and distance of TV watching

\begin{tabular}{|c|c|c|c|c|}
\hline \multirow{2}{*}{$\begin{array}{c}\text { Distance } \\
\text { (feet) }\end{array}$} & \multicolumn{3}{|c|}{ Visual Acuity } & \multirow{2}{*}{ Total } \\
\cline { 2 - 5 } & $6 / 6$ & $6 / 9-6 / 12$ & $6 / 18-6 / 60$ & {$[\%]$} \\
\hline 0 & {$[\%]$} & {$[\%]$} & {$[\%]$} & 93 \\
& 82 & 9 & 2 & {$[100]$} \\
\hline$<5$ & $188.2]$ & {$[9.7]$} & {$[2.1]$} & 129 \\
& {$[79.1]$} & {$[11.6]$} & {$[9.3]$} & {$[100]$} \\
\hline $5-10$ & 801 & 81 & 32 & 914 \\
& {$[87.6]$} & {$[8.9]$} & {$[3.5]$} & {$[100]$} \\
\hline$\geq 10$ & 108 & 12 & 9 & 129 \\
& {$[83.7]$} & {$[9.3]$} & {$[7.0]$} & {$[100]$} \\
\hline Total & 1093 & 117 & 55 & 1265 \\
& {$[86.4]$} & {$[9.3]$} & {$[4.3]$} & {$[100]$} \\
\hline
\end{tabular}

$\square^{2}=14.002(\mathrm{df}-6), \mathrm{P}<0.05^{*}$

Table III shows the prevalence of defective vision was found 
to be more in students who watched TV for longer duration. The association between duration of TV watching with defective vision was not found to be significant.

\section{Figure 3}

Table: III relation of defective vision with duration of TV watching

\begin{tabular}{|c|c|c|c|c|}
\hline \multirow{3}{*}{$\begin{array}{c}\text { Duration } \\
\text { (hrs) }\end{array}$} & \multicolumn{3}{|c|}{ Visual Acuity } & \multirow{2}{*}{ Total } \\
\cline { 2 - 4 } & $6 / 6$ & $6 / 9-6 / 12$ & $6 / 18-6 / 60$ & \\
\hline 0 & {$[\%]$} & {$[\%]$} & {$[\%]$} & 2 \\
& 82 & 9 & 2 & 93 \\
& {$[88.2]$} & {$[9.7]$} & {$[2.1]$} & {$[100]$} \\
\hline $1-2$ & 561 & 50 & 23 & 129 \\
& {$[88.5]$} & {$[7.9]$} & {$[3.6]$} & {$[100]$} \\
\hline $3-5$ & 450 & 58 & 30 & 1043 \\
& {$[83.6]$} & {$[10.8]$} & {$[5.6]$} & {$[100]$} \\
\hline Total & 1093 & 117 & 55 & 1265 \\
& {$[86.4]$} & {$[9.3]$} & {$[4.3]$} & {$[100]$} \\
\hline
\end{tabular}

$\square^{2}=6.60(\mathrm{df}-4), \mathrm{P}>0.1$

\section{DISCUSSION}

Out of total 1265, 93 students did not watch TV. Out of 1172 students watching TV, 161 students $(13.7 \%)$ had defective vision. Out of 109 students $(9.3 \%)$ who watched TV in darkness, 24 students $(22 \%)$ had defective vision. The defective vision was significantly associated with darkness during TV viewing $(\mathrm{p}<0.01)$. Dr.Anand Shroff in one of his articles has suggested that instead of watching TV in a dark room a well-lit room with white light [tube light] is ideal ${ }^{7}$. Similarly Admin in his article has suggested that while watching TV there should be shining light in the room ${ }^{8}$. Another article also suggests that overall soft lighting can make television viewing easier?

Out of total 1172 students who watched TV, 129 students (11\%) who watched TV from a distance of less then 5 feet, 27 students $(20.9 \%)$ had defective vision. Out of 914 students (78\%) who watched TV from a distance 5-10 feet, 113 students $(12.4 \%$ ) had defective vision and out of 129 students $(11 \%)$ who watched TV from a distance $>10$ feet, 21 students $(16.3 \%)$ had defective vision. It was observed that TV watching from a distance of less then 5 feet was significantly associated with defective vision $(\mathrm{p}<0.05)$.

According to Dr.Anand Shroff, television should be watched from a distance of 4 meters or more ${ }^{7}$. Article "Elementary School Age Children and Their Eyes" suggested that children should be sited at least 3 meters ( 8 to 10 feet) away from the television screen ${ }^{9}$. Admin suggested the distance between eyes and the television screen should be always 6-8 times of the size of the television screen ${ }^{8}$.

In this study it was observed that prevalence of defective vision was more in cases of longer duration of TV watching, but the association of duration was not found to be significant with defective vision. Dr Mihir Kothari has suggested that extended close viewing of a computer monitor (or TV) can cause eye strain and fatigue as reflected by neck and shoulder problems, headache, blurred vision, double vision, red or watery or dry eyes and pain around the eyes and face. Extended close work can also cause a person to become more near-sighted (myopic), requiring the need for stronger corrective lenses ${ }^{2}$. Admin suggested that it is better to have a rest for 5-10 minutes after watching TV for 30 minutes and never watch TV for an hour continuously ${ }^{8}$.

Brit eye specialists have revealed that games and television are responsible for impairing a child's visual development and a major cause of damaging children's reading and learning abilities ${ }^{10}$.

\section{CONCLUSION}

Poor vision in childhood affects performance in school or at work and has a negative influence on the future life of the child, so it is important to take care of eyes during the development of a child. There should be close watch on distance and duration of TV watching and proper light should be there in the room.

\section{STRENGTH}

The age group and rural setting and extensive data available are strengths of the study.

\section{References}

1. Susan R Johnson. Strangers in our homes: TV and Our Children's Minds.1999. Available from

http://home.datacomm.ch/rezamusic/tv_j ohnson.html. 2. Dr Mihir Kothari. Q and Archives. Available from http://www.ohiolionseyere search.com/QandArchives.htm. 3. Gretchyn Bailey. Vision Problems of School children. 2010 June. Available from

http://www.allaboutvision.com/parents/schoolage.htm. 4. Vision screening in school children. A training module. New Delhi: The Type setters:1992.p.5.

5. Govt. of India. National Programme for Control of Blindness. Quarterly News letter 2007; Vol 2.

6 . Health dialogue. A forum for the exchange of new and views on primary health care in India. Inveno. 44 jan-march 2006.p.1.

7. Dr.Anand Shroff. All You Need To Know About Eyes And Eye Care For Kids. Available from

http://www.whereincity.com/medical/topic/eye-and-vision/ar ticles /252.htm

8. Admin. Eight Step Methods to Protect Young Children's

Eyes. 2009 Dec. Available from enjoyvisionlife.com.

9. HealthLink BC File \#53b. 2007 August. Elementary

School Age Children and Their Eyes Eye Safety for

Children. Available from http://www.healthlinkbc.ca/ healthfiles/hfile53b.stm .

10. TV To Damage Children's Eyesight. Available from 


\section{Author Information}

\section{Sharma Seema}

Assistant Professor, Department of Community Medicine, MAMC

\section{Vashisht BM}

Professor, Department of Community Medicine, PGIMS

\section{Khurana AK}

Senior Professor, Regional Institute of Ophthalmology, PGIMS

\section{Kalhan Minakshi}

Assistant Professor, Department of Community Medicine, PGIMS

\section{Goel Manish}

Assistant Professor, Department of Community Medicine, PGIMS 